sers _zusammenschmolz und eine homogene Masse bildete. Diese zerrieb ich mit 2 Gewichttheilen trocknen Natriumoxydcarbonats und 8 Gewichttheilen Kaliumoxydnitrats zu Pulver, und schuittete kleine Portionen desselben, so oft in einen roth gliihenden Tiegel bis alles verbrannt war. Im Gefäss fand sich eine weisse Salzmasse, die in Wasser gelöst und mit Salpetersäure ïbersältigt wurde. Aus dieser Flüssigkeit fâllte ich die entstandene Schwefelsäure mit einem Bariumsalze und berechnete den Niederschlag auf Schwefel.

Liess ich das Natriumoxydcarbonat weg, so entzündete sich die Masse wie Schiesspulver und bildete einen langsam brennenden umgekehrten funkensprühenden Feuerkegel. Nahm ich nur die Hälfte dẹ Nitrats, so liess sich aus der zurückgebliebenen Salzmasse Schwefel ausscheiden.

\title{
Ueber die Zusammensetzung des Fuselöls von Kartoffelnbranutwein;
}

\author{
von \\ J. $D u m a s$.
}

(Auszug aus den Annales de Chim. et de Phys. LVI. 3140)

Es ist bekannt, dass das Fuselöl, welches bei der Rectifikation des Bránntweins erhalten wird, die Ursache des Fuselgeschmacks und Fuselgeruchs desselben ist. Sche ele hat zuerst die Existenz dieses Oels nachgewiesen in dem Kornbranntwein; er fand, dass es sich bei der Kälte aus diesem abschied. Fourcroy und Vauquelin bewiesen, dass dieses Oel kein Produkt der Gährung sey, wie einige angenommen haben, sondern dass es gebildet im Getraide, 
wie in der Gerste z. B., enthallen sey, aus der man nach Auswaschen mit Wasser dieses Oel durch Alkohol ausziehen kann. In der neuesten Zeit fand Payen, dass der Sitz dieses Oels, wenigstens bei den Kartoffeln, das Stärkmehl ist, und zwar der tegumentaire Theil der Stä:kmehlkörnchen selbst.

Die Angaben ïber die Eigenschaften dieses Oels weichen von einander $a b$, je nach der Natur der Produkte, die man stuđarte. Die, welche das Oel aus Kornbranntwein untersuchten, fanden ein krystallisirbares Oel, welches sich nur scluwierig verfliichtigen liess, mehr oder weniger dabei zersetzt werdend, und einen Fettfleck auf dem Papiere machend. Diese Charaktere sind mehr die eines fetten Oels als eines ätherischen.

Das Kartoffelnficselöl hat nach Pelletan alle Eigenschaften eines ätherischen Oels und nähert sich in vielen Reactionen selbst dem Alkohol.

Wegen dieses letzten Umstandes wünschte ich besonders, dieses Oel zu untersuchen. Dasjenige, welches ich aus der Fabrik des Herm Dubrünfaut erhielt, war röthlichgelb, von böchst unangenehmen Geruch. Das Athmen einer damit beladenen Luft bewirkte Uebelkeit und Schwere des Kopfes. Ueber kohlensaures Kali destillirt nimmt es einen Geruch nach Reinettenäpfeln oder Salpeteräther an.

Obgleich dieses Oel im rohen Zustande im Wasser unlöslich zu seyn scheint, so schliesst es doch eine grosse Quantität Alkohol ein, den man in Folge der verschiedenen Flüchtigkeit dieser Körper abscheiden kann. Wird das Oel behutsam destillirt, so erhält man einen Rückstand, der bei 130 bis $132^{\circ} \mathrm{C}$. kocht, und den man für sich sammelt. Wenn man die ersten Produkte absondert und die mittlern besonders auffängt, so kann man durch eine sorgfältige neue 
Destillation derselben eine neue Quantität des bei 130 bis $132^{\circ} \mathrm{C}$. kochenden Oels erhalten.

Das so erhaltene Oel gab durch Rectifikationen endlich ein homogenes Produkt, welches bei $131,5^{\circ}$ siedete. Dieses Oel war farblos, durchsichtig und von widrig - eckelhaftem Geruch. Es besteht aus Kohlenstoff, Sauerstoff und Wasserstoff, in Verhältnissen, die einige Beziehung zum Alkohol und Aether andeuten; wahrscheinlicher ist es aber, dass es zur Familie der Kampferarten oder ätherischen Oele gehört.

I. 0,268 Oel gaben o,33o Wasser und 0,672 Kohlensäure.

II. 0,372 Oel gaben 0,457 Wasser und 0,923 Kohlen. säure.

I.

II.

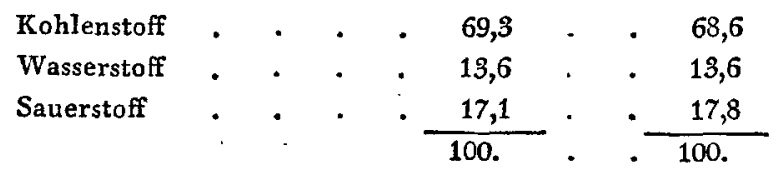

$\mathrm{Da}$ dieses Oel auf eine regelmässige Weise siedet, so wurde auch die Dichtigkeit seines Dampfes bestimmt, die sich in verschiedenen Versuchen konstant zeigte. Man erhielt :

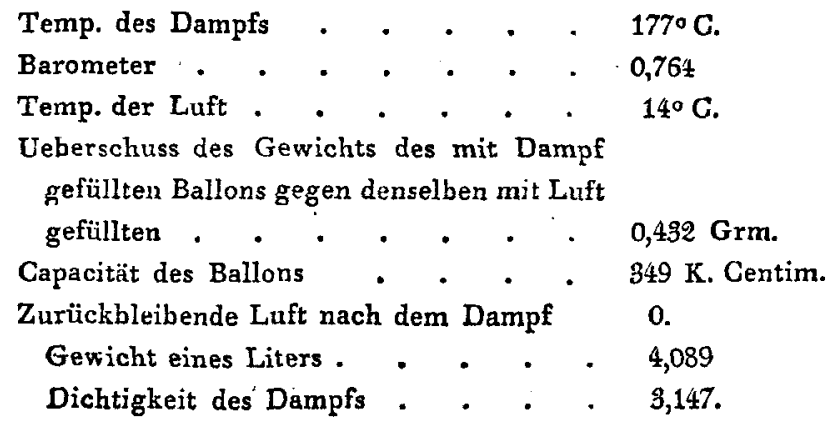


Diese Resultate führen auf die Formel $\mathrm{C}^{10} \mathrm{H}^{12} 0$. Diese giebt in der That:

$$
\begin{array}{lllllrlll}
\mathbf{C}^{10} & \cdot & \cdot & \cdot & \cdot & 382,6 & \cdot & \cdot & 68,6 \\
\mathrm{H}^{12} & \cdot & \cdot & \cdot & \cdot & 75,0 & \cdot & \cdot & 13,4 \\
\mathrm{O} & \cdot & \cdot & \cdot & \cdot & 100,0 & \cdot & \cdot & 18,0 \\
\hline & & & & & 557,6 . & \cdot & \cdot & 100,0 .
\end{array}
$$

Für die Dichtigkeit des Dampfs würde das Resultat sich ergeben :

$$
\begin{array}{lllllll}
\mathbf{C} & \cdot & \cdot & \cdot & \cdot & \cdot & 4,2160 \\
\mathbf{H}^{12} & \cdot & \cdot & \cdot & \cdot & \cdot & 0,8256 \\
\mathrm{O} & \cdot & \cdot & \cdot & \cdot & \cdot \frac{1,1026}{6,1442} \\
& & & & & & \frac{}{2}
\end{array}
$$

Jedes Volum des Dampfes schliesst hiernach $\mathrm{C}^{5} \mathrm{H}^{6} \mathrm{O}^{\frac{\mathrm{T}}{2}}$ ein, wodurch sich dieses Oel den Kampferarten anreihet *).

*) Man unterscheidet $\mathbf{2 w e i e r l e i ~ F u s e l o ̈ l e , ~ e i n ~ f e s t e s ~ u n d ~ e i n ~ f l u ̈ s - ~}$ siges. Das Kornfuselöl ist von $S$ cheele und Hermbstädt, vorzüglich aber von $\mathrm{G}$ ehl en u. Kor te untersucht. (Schweigg. Journ. $I$. 273.) Es nährt sich in mehren Eigenschaften den fetten Körpern, und dies ist der Grund, weshalb Schrader vermuthete, dass es bei der Gährung oder bei wenigstens rascher, Destillation aus dem im Getraide vorhandenen Fette gebildet werde. Ferner hat Buchner ein flüssiges Fuselöl des Kornbranntweins beschrieben (Dessen Repert. $X X I V .270$ ). Das Fuselöl des Kartoffelnbranntweins, von dem Pelletan handelt, war ebenfalls dünn, von 0,821 spec. Gewicht, bei $20^{\circ} \mathrm{C}$. aber wurcle es fest. Vergl. Hensmann's Denkschrift über die geistigen Flüssigk. Uebers. von Brandes.

D. Red. 